\title{
Estudo sorológico de isolados de Brachyspira pilosicoli de suínos da região sul do Brasil
}

\author{
Serological analysis of Brachyspira pilosicoli strains isolated from pigs in Southern Brazil \\ Luís Eduardo Razia ${ }^{1}$, Tania Allen Coutinho², Sandra Maria Borowski ${ }^{3}$, William Asanome ${ }^{2}$, \\ Felipe Leonardo Köller² \& David Emilio Santos Neves de Barcellos ${ }^{2}$
}

\begin{abstract}
RESUMO
A colite espiroquetal, doença infecciosa causada pela Brachyspira pilosicoli, foi recentemente descrita no Brasil e causa significativas perdas à produção suinícola por diarréia, perda de peso e piora da conversão alimentar. $\mathrm{O}$ agente é anaeróbico, fastidioso e a infecção causada pelo mesmo de difícil diagnóstico laboratorial. Dessa forma, o desenvolvimento de técnicas de diagnóstico nessa área apresenta particular relevância. No presente trabalho buscou-se analisar isolados da bactéria através da técnica sorológica da microaglutinação. Foram produzidos em coelhos soros hiperimunes contra duas amostras de referência de B. pilosicoli, 20 amostras da bactéria isoladas no Estado do Rio Grande do Sul e uma cepa de referência de outra espiroqueta patogênica (B. hyodysenteriae). Reagindo todas as cepas contra todos os soros, foram detectados vários padrões de reatividade cruzado. Pela grande variabilidade dos títulos, não houve possibilidade estabelecer um padrão sorológico capaz de permitir um agrupamento das bactérias analisadas em sorotipos. A existência dessa discrepância nas aglutinações realizadas com soros homólogos e heterólogos sugere compartilhamento de antígenos (cadeias laterais de açúcares) entre as amostras ou diferenças de quantidade dos açúcares na membrana celular externa. Por reagir contra todas as cepas de B. pilosicoli com título superiores a 1:1120, o antissoro produzido contra a amostra SIPV14 poderia ser utilizado em provas de diagnóstico, como a imuno-histoquímica e ELISA. Por reagir com todos os soros com títulos superiores a 1:2880, a cepa SIPV42 seria a mais indicada para ser utilizada para a produção de vacina para a prevenção da infecção intestinal contra a B. pilosicoli (colite espiroquetal).
\end{abstract}

Descritores: Brachyspira pilosicoli, suínos, sorologia, microaglutinação, colite espiroquetal.

\begin{abstract}
Spirochetal colitis, an infectious disease caused by Brachyspira pilosicoli, was recently diagnosed in the State of Rio Grande do Sul, Brazil, and causes significant losses to the pig industry because it produces diarrhea and impairment in feed conversion. The agent is anaerobic, has fastidious growth and it is difficult to achieve a laboratory diagnosis for the infection. This indicates a particular importance for the development of diagnostic techniques in this area. In the present work, different strains of the bacteria were analyzed through a microagglutination technique. Hyper immune serum was produced in rabbits against two reference strains of B. pilosicoli, 20 strains of the bacteria isolated in the State of Rio Grande do Sul, Brazil, and one reference strain of another pathogenic spirochete (B. hyodysenteriae). Reacting all strains against all anti-sera, several reactivity patterns were detected. Because of the wide variability of titers, it was not possible to establish a serological scheme that could permit grouping the isolated strains in defined serotypes. The presence of such discrepancies using homologous and heterologous antisera suggest sharing of antigens (lateral chains of sugars) between strains or differences in the structure of sugars in the bacterial external membrane. Because it reacted against all strains of B. pilosicoli with titers above 1:1120, antiserum produced against the strain SPIV14 could be used in diagnostic tests, such as immunohistochemistry or ELISA. Because it reacted against all tested sera with titers above 1:2880, the strain SPIV42 would be the most indicated for production of a vaccine against the infection with B. pilosicoli (spirochetal colitis).
\end{abstract}

Key words: Brachyspira pilosicoli, swine, serology, microagglutination, spirochetal colitis. 


\section{INTRODUÇÃO}

A Colite Espiroquetal (CE) é uma doença bacteriana dos suínos causada por uma espiroqueta, a Brachyspira (B.) pilosicoli. É uma forma sub clínica de colite que cursa com diarréia, perda de peso e prejuízo na conversão alimentar. No Brasil, Barcellos et al. [3] estudaram a importância relativa de espécies da bactéria como causa de diarréia em suínos no Estado do Rio Grande do Sul, detectando espécies patogênicas (B. pilosicoli e B. hyodysenteriae) em 13 das 17 granjas amostradas. Os dados ressaltam a significância dessas espiroquetas, sugerindo que as infecções espiroquetais sejam incluídas no diagnóstico diferencial das diarréias nas fases de recria e terminação.

O desenvolvimento in vitro da B. pilosicoli é considerado fastidioso. Métodos moleculares suficientemente sensíveis e específicos foram desenvolvidos para permitir a diferenciação das espiroquetas intestinais dos suínos, mas requerem alto investimento para uso rotina de diagnóstico.

O conhecimento das características sorológicas das B. pilosicoli mais frequentes numa região poderia viabilizar a produção de vacinas, visto que se identifica qual isolado produz a resposta antigênica de maior eficiência. Poder-se-ia também definir quais as melhores cepas para a produção de antissoros, com a finalidade de aplicação em imuno-histoquímica e na realização de monitorias sorológicas. A identidade sorológica dos isolados também serviria como marcador epidemiológico para o estudo do perfil da infecção em determinadas regiões.

O objetivo do presente trabalho foi o de analisar a diversidade sorológica de cepas de B. pilosicoli previamente isoladas de suínos do sul do Brasil, utilizando uma técnica de microaglutinação.

\section{MATERIAIS E MÉTODOS}

\section{Cepas de Brachyspira pilosicoli utilizadas}

As seguintes cepas de referência foram obtidas através do Dr. Gerald Duhamel, Department of Veterinary Clinical Studies, Lincoln, Nebraska, USA: - P43/6/78, ATCC 51139, cepa de referência de $B$. pilosicoli [22];

- SP16, ATCC 49776, isolado humano de B. pilosicoli, proveniente dos Estados Unidos [5];
- B78, ATCC 27164, cepa de referência de $B$. hyodysenteriae [11].

As amostras de campo SIPV 1, 8, 9, 12, 13, $14,15,16,18,19,20,22,23,36,37,38,39,40,42$ e 43 haviam sido isoladas de suínos com diarréia da região sul do Brasil [1] e estavam disponíveis na Faculdade de Veterinária da UFRGS.

Todas as bactérias estavam liofilizadas e mantidas sob refrigeração até o momento de sua ressuspensão e cultura, feita com meio líquido PRAS preparado como descrito por Kunkle et al. [12], em tubos tipo Hungate. As suspensões bacterianas utilizadas para as inoculações em coelhos e para os teste de microaglutinação foram corrigidas para uma concentração de $1 \times 10^{9}$ células $/ \mathrm{mL}$, através de contagem em câmara de Neubauer, utilizando microscopia de campo escuro.

\section{Obtenção dos soros hiperimunes}

O soro hiperimune policlonal usado para a técnica de microaglutinação foi obtido através da inoculação de coelhos, usando 2 animais para cada uma das 23 cepas (total de 46), usando um protocolo padrão [19]. A via de inoculação foi a intramuscular profunda, na forma de uma emulsão aquosa-oleosa obtida com uma suspensão inativada de B. pilosicoli (padronizadas para a concentração de $1 \times 10^{9}$ células/ $\mathrm{mL}$ ) em adjuvante completo de Freund (DIFCO). Após 21 dias, foram realizadas quatro inoculações intravenosas de $1 \mathrm{~mL}$ do antígeno aquoso, a cada três dias. Decorridos quatro dias após a última inoculação intravenosa, os coelhos foram sangrados e o soro obtido foi submetido ao teste de microaglutinação contra a amostra homóloga. Os soros foram armazenados em frascos tipo Falcon sem conservantes e mantidos congelados a $-20^{\circ} \mathrm{C}$ até o uso.

\section{Teste de microaglutinação}

O teste de microaglutinação foi realizado por observação direta em microscopia de campo escuro, numa magnificação de 400 vezes. Foi utilizado uma mistura de células de Brachyspira e diferentes diluições de anticorpos policlonais em placas de microtitulação com fundo plano, de 96 cavidades [15]. Um teste similar tem sido usado para detecção e quantificação de anticorpos séricos de Leptospira [21]. O tempo de incubação foi de 2-4 horas, a uma temperatura de $30^{\circ} \mathrm{C}$. 
Cada uma das cepas foi exposta aos antissoros produzidos contra si e contra as outras cepas. Uma densidade de cerca de 100 espiroquetas por campo microscópico foi utilizada. A aglutinação superior a $50 \%$ foi classificada como positiva [15]. A leitura das placas foi realizada em microscópio de campo escuro, sob aumento de 40X. O controle negativo utilizado foi PBS (Phosphate Buffer Saline).

Os títulos foram obtidos como a recíproca da mais alta diluição de antissoro capaz de aglutinar o antígeno, (23 amostras de antígenos $\mathrm{x} 23$ antissoros = 529 resultados), sendo o procedimento de microaglutinação repetido cinco vezes em dias diversos, totalizando 2645 microaglutinações. Os resultados foram expressos como a média entre os títulos das repetições.

\section{RESULTADOS}

Uma tabulação dos resultados das microaglutinações feitas com as culturas de Brachyspira isoladas na região sul do Brasil e os respectivos antissoros policlonais são apresentados no Quadro 1.

Em 94 resultados de microaglutinações (29\%) não houve aglutinação e/ou lise, indicando a ausência de reação antígeno-anticorpo.

O menor título resultante da microaglutinação feita com um antígeno e seu antissoro policlonal homólogo foi 1:1600, obtido com a amostra SIPV20, enquanto o maior título foi 1:51200, com a amostra SIPV38. O título médio de todas as microaglutinações homólogas foi 1:6400. O antissoro produzido contra a amostra SIPV8 não reagiu contra o antígeno homólogo. Não foi possível determinar a causa da falha do coelho em apresentar resposta sorológica ao antígeno inoculado. Em 8 soros (SIPV01, 09, 16, $19,38,39,40$ e 42 ), de um total de 19 , a reação homóloga foi maior do que todas as reações heterólogas. Os títulos obtidos em provas feitas com espiroquetas de outro gênero (B. hyodysenteriae) e da cepa de $B$. pilosicoli isolada de seres humanos (SP16) foram substancialmente menores do que aqueles obtidos contra os isolados de B. pilosicoli de origem suína (Quadro 1).

Foi realizado um agrupamento dos soros na forma de agrupamentos ("clusters") de similaridade, usando como critério a ausência total de reatividade a um determinado soro (Quadro 2). Esse parâmetro para tentar julgar a similaridade foi considerado adequado, pois o menor título obtido foi de 1:640 e, dessa forma, a distância entre 0 a 1:640 foi de mais de 4 logaritmos. Essa diferença foi superior à variação encontrada entre as repetições realizadas com uma mesma amostra em dias consecutivos, indicando a viabilidade de usar esse critério como forma de analisar diferenças antigênicas entre as amostras testadas. Por esse critério, os soros contra as amostras 9, 12, 23 e 37 tiveram semelhança parcial de títulos, com a formação de blocos com resultados semelhantes, não sendo possível a identificação de sorogrupos. Situação similar foi detectada com os soros 16, 18, 19, 20, 22, 38, 40, 42, 43 e com o grupo 13,36 e 39 .

O soro produzido contra a cepa SIPV14 reagiu contra todos os antígenos aos quais foi exposto, com título mínimo de 1:1120. Já o antígeno produzido com a amostra SIPV42 provocou reação de microaglutinação em todos os soros aos quais foi exposto, com título mínimo de 1:2880.

Através da análise dos títulos numéricos, procurou-se detectar grupos de cepas com resultados de microaglutinação semelhantes, com o objetivo de classificá-las em sorogrupos. Verificou-se que isso não foi possível, devido ao grande número de reações cruzadas entre as amostras.

Foi observada boa concordância em relação à presença de variação em resultados dos títulos de microaglutinação lidos em dias diferentes, pois $98 \%$ dos resultados foram iguais em dias consecutivos e a diferença máxima de títulos entre resultados foi de dois logaritmos (observado em 7 entre as 19 amostras, SIPV01, 09, 14, 19, 20, 22, 37).

Quatorze soros reagiram contra o antígeno SIPV01, 7 contra o antígeno SIPV08, 10 contra o antígeno SIPV09, 11 contra o antígeno SIPV12, 17 contra o antígeno SIPV13, 19 contra o antígeno SIPV14, 18 contra o antígeno SIPV15, 15 contra o antígeno SIPV16, 14 contra o antígeno SIPV18, 12 contra o antígeno SIPV19, 10 contra o antígeno SIPV20, 15 contra o antígeno SIPV22, 16 contra o antígeno SIPV23, 13 contra o antígeno SIPV36, 13 contra o antígeno SIPV37, 13 contra o antígeno SIPV38, 17 contra o antígeno SIPV39, 15 contra o antígeno SIPV40, 13 contra o antígeno SIPV42 e 13 contra o antígeno SIPV43. 


\section{DISCUSSÃO}

Grande parte dos testes sorológicos desenvolvidos para espiroquetas intestinais objetivou o diagnóstico de Brachyspira hyodysenteriae [1]. Esses testes buscavam detectar oligossacarídeos da membrana celular externa [9], mas tiveram problemas ao constatar que poderiam ocorrer reações cruzadas entre esses antígenos, bem como para os antígenos flagelares.

Uma alternativa proposta foi adsorver soros policlonais com antígenos de espiroquetas relacionadas, que poderiam estar induzindo as reações cruzadas [9]. Isso, entretanto, causou uma redução nos títulos obtidos, assim como na sensibilidade do teste. Além disso, o fato de não terem sido baseados em antígenos espécie-específicos, levou a uma baixa especificidade e/ ou sensibilidade e requereu um conhecimento dos sorotipos dos organismos presentes nos rebanhos testados [16].

Uma característica importante dos testes baseados em aglutininas é o fato de poderem apresentar reações cruzadas significativas com outras espiroquetas patogênicas ou não, pois compartilham um série de antígenos comuns a essas espécies [1]. Entretanto, mesmo com essa ressalva, conforme citado anteriormente, foi possível desenvolver um sistema de classificação sorológica para a $B$. hyodysenteriae usando um teste baseado em teste de precipitação em gel [6].

Ao iniciar o presente trabalho, a expectativa era a de desenvolver um sistema de classificação sorológica para a B. pilosicoli. Tal pretensão se baseava em um trabalho realizado anteriormente [2], em que havia sido usado apenas um antissoro produzido contra a amostra padrão de B. pilosicoli ( $\mathrm{P} 43 / 6 /$ 78) para reagir contra as diversas cepas de $B$. pilosicoli que havíamos isolado de casos de diarréia em suínos no Estado do Rio Grande do Sul. Usando essa estratégia, havia sido possível classificar os 19 isolados brasileiros em 3 grupos, encorajando-nos a prosseguir estudos nesse sentido. Foram produzidos soros contra todas essas amostras e realizadas aglutinações cruzadas, de forma a analisar de maneira completa as afinidades e diferenças imunológicas entre as diversas cepas.

Os resultados indicaram existir uma alta diversidade sorológica ao serem analisados os resulta- dos dos testes de microaglutinação. Houve também uma alta ocorrência de reações de auto-aglutinação de células espiroquetais por ocasião da diluição anterior à realização dos testes. Essa reação poderia representar a presença de cultivos na forma rugosa, em que a falta ou redução das cadeias de polissacarídeos superficiais dificultaria ou impediria a manutenção das bactérias em suspensão na solução PBS em que são misturadas para a realização da microaglutinação [14]. Coletivamente, esses fatores impediram a estratificação por títulos baseado nos resultados de microaglutinação, não tendo sido possível estabelecer um esquema sorológico capaz de classificar os isolados.

Em 29\% dos testes não houve aglutinação, significando que reações antígeno-anticorpo não ocorreram. Isso poderia ser explicado pela ausência de determinantes antigênicos (cadeias laterais de açúcares) homólogos aos soros usados nessa prova sorológica. Um aspecto interessante foi que o menor título, depois daqueles em que não houve reação (título 0 ) foi 1:640, indicando que, quando houve reação, esta ocorreu de maneira evidente, com títulos facilmente detectáveis.

Para o teste de microaglutinação, é exigida a utilização de antígenos obtidos a partir de cultivos em fase logarítmica, em meio líquido. Esse é um detalhe importante quando se trabalha com espiroquetas do gênero Brachyspira, pois são organismos de crescimento fastidioso, que exigem condições especiais para sua multiplicação, como atmosfera de anaerobiose, além de crescimento num meio líquido pré-reduzido e sob agitação. Devido a essa relativa complexidade, não foi possível obter uma quantidade suficiente de antígeno correspondente à cepa SIPV43 no momento da realização das microaglutinações.

Analisando o Quadro 2, que utiliza como critério para a classificação a presença de resultado negativo (falha em aglutinar), foi possível identificar blocos ("clusters") de resultados semelhantes, o que poderia indicar um grau relação entre as cepas formadoras de tais agrupamentos. Foram formados pelo menos 3 blocos, o primeiro com os antissoros contra as amostras SIPV9 12, 23 e 37 que não reagiram com os antígenos SIPV14, 15, 16, 18, 19, 20 e 22. O segundo bloco contém os resultados obtidos das microaglutinações feitas com os antissoros SIPV16, 18, 19 e 20 e os antígenos SIPV08, 09, 12 e 13. O terceiro bloco foi formado pelos antissoros SIPV16, 18, 19, 20, 22, 38, 40, 42 e 43 


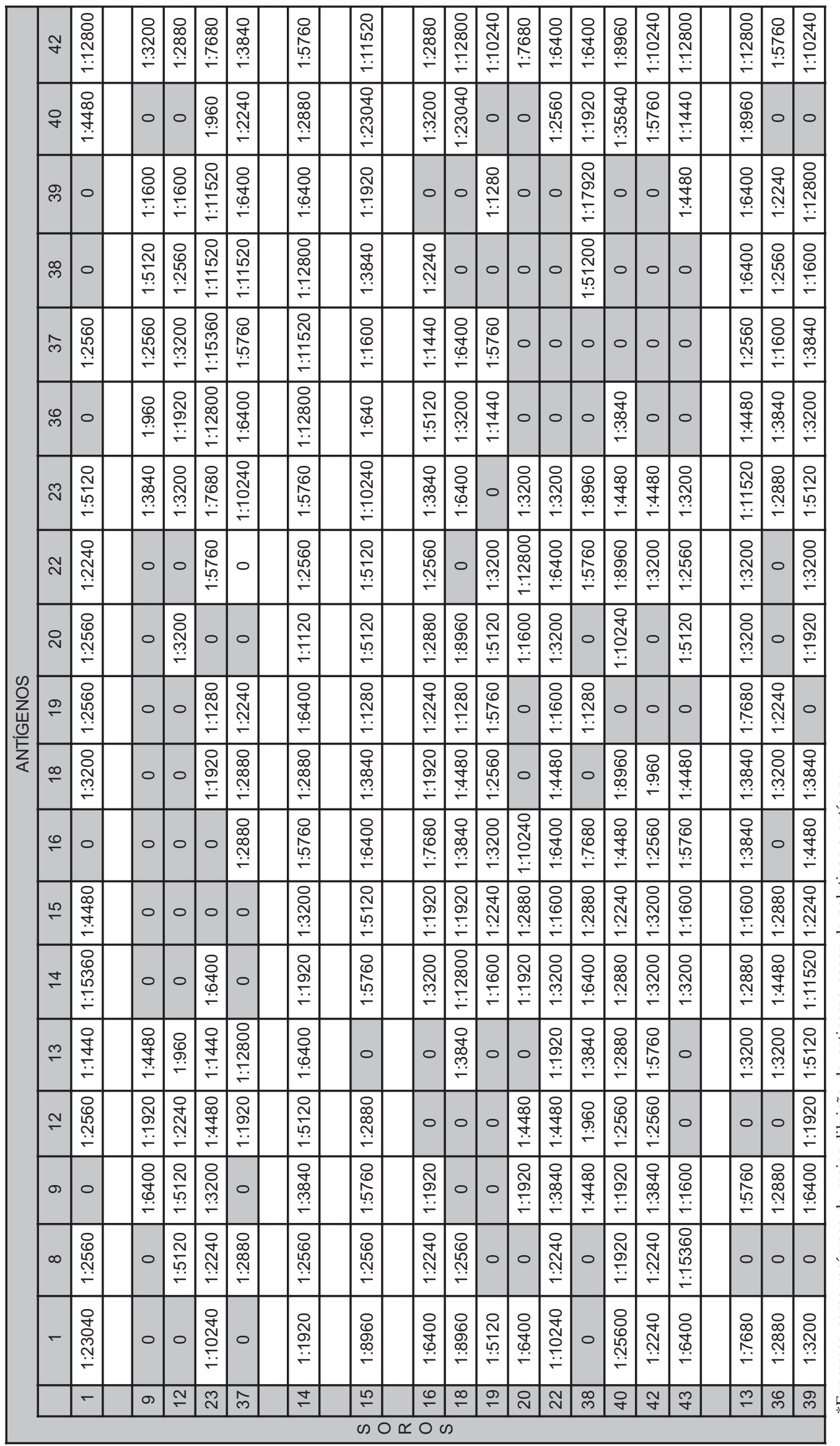


e os antígenos SIPV36, 37, 38, 39 e 40. Entretanto, essas homologias não foram totais e, quando foram analisados os títulos das reações contra os antígenos em que houve reação positiva, notou-se muita variação. Além disso, ao ser observada a Quadro 2 comparando as reações num sentido oposto (antígenos contra antissoros), verificou-se que os resultados nem sempre foram concordantes, enfatizando ainda mais as evidências de ampla variação antigênica entre os diferentes cultivos.

Esquemas de classificação sorológica para B. hyodysenteriae haviam sido publicados anteriormente $[4,6,13]$. Através desses esquemas, foi possível definir nove sorotipos. Para a $B$. pilosicoli, não encontramos na literatura avaliações similares. Nossos resultados são opostos aos obtidos pelos autores anteriormente citados para a $B$. hyodysenteriae, pois não foi possível definir um esquema de classificação sorológica para a B. pilosicoli, sugerindo dificuldade em classificar essa espécie bacteriana com o uso da sorologia. Tais observações possivelmente reflitam uma grande variabilidade antigênica da membrana externa da B. pilosicoli, principalmente dos açúcares do LOS, principal elemento imunogênico externo da bactéria. Também é possível que diferentes clones estejam presentes nos diversos isolados. Epitopos presentes nesses açúcares seriam compartilhados por diferentes amostras da espécie, induzindo a uma alta ocorrência de reações sorológicas cruzadas. [6,23].

A variação verificada nos resultados obtidos com o teste de microaglutinação lidos em dias diferentes, por ocasião das cinco repetições realizadas, foi de apenas $2 \%$. Isso confirmou a boa repetibilidade desse teste diagnóstico, que vem sendo utilizado há anos para diagnóstico de outra espiroqueta de interesse médico e veterinário, as bactérias do gênero Leptospira [21].

Nos resultados foi constatado que alguns títulos de reação heterólogos foram maiores que os homólogos. A diversidade das cadeias laterais de polissacarídeos na membrana das espiroquetas, fazendo com que epitopos, ainda que em pouca quantidade, demonstrem grande especificidade ou sejam mais expostos a anticorpos de um soro heterólogo poderia explicar essa constatação, provocando uma reação maior do que aquela que seria específica para aquele antissoro. Outra possibilidade a ser considerada é que tenha havido problemas na viabilidade e riqueza dos cultivos usados para a produção dos soros hiperimunes ou dos antígenos usados nos testes. Esses problemas poderiam ter proporcionado condições disgenésicas a determinadas cepas, provocando variações na quantidade ou qualidade de açúcares (antígenos) superficiais. Ao serem inoculadas em coelhos, poderia haver uma resposta imune com especificidade comprometida em relação à $B$. pilosicoli.

Uma outra utilidade do conhecimento das características imunogênicas da $B$. pilosicoli poderia ser o desenvolvimento de testes de diagnóstico baseados em reações imunológicas. Um exemplo seria o teste de imuno-histoquímica, que é usado diretamente em cortes histológicos para chegar a um diagnóstico rápido e específico das infecções intestinas pelas Brachyspira spp. Para selecionar um soro a ser usado numa das reações desse tipo (imunoperoxidase indireta), o soro ideal seria aquele que reagisse contra o maior número possível de antígenos (Brachyspiras), para aumentar a sua sensibilidade [18].

No nosso caso, foi identificada uma amostra que apresentou essa característica (SIPV14), pois reagiu com títulos acima de 1:1120 contra todos os antígenos testados. A utilização desse soro permitirá aprimorar o diagnóstico da infecção que atualmente vem sendo usado rotineiramente no setor de Patologia da Faculdade de Veterinária da UFRGS. Esse teste atualmente vem sendo realizado com um soro produzido contra a cepa de referência da espécie, a P43/6/78, que foi menos eficiente do que o soro contra a cepa SIPV14 na nossa avaliação, pois reagiu apenas contra 10 entre os 19 antígenos testados $(52,63 \%)$. Com a inclusão no teste do soro agora detectado, capaz de reagir com 19/19 (100\%) entre as amostras testadas, é previsível um aumento de sensibilidade do teste de diagnóstico atualmente em uso entre nós.

Monitorias sorológicas facilitam o controle dos níveis de infecção de diversas doenças, tendo a vantagem de obter rapidamente informações sobre o status sanitário de uma granja, ou de um único animal [20]. Um dos testes que vem sendo mais usados para tal é o ensaio imunoenzimático do tipo ELISA. Essa prova apresenta a vantagem de excluir as variações produzidas pela interpretação subjetiva do MAT, além de serem automatizáveis.

No caso das $B$. pilosicoli isoladas até o momento no Brasil, poderia ser executada uma prova indireta com o antissoro produzido contra a cepa 
SIPV14, que seria capaz de reconhecer, com títulos altos, todas as cepas isoladas no nosso meio.

Uma observação interessante foi que a amostra SIPV42 provocou reações de microaglutinação, com títulos maiores do que 1:2880, para todos os soros com os quais esse antígeno foi testado. Isso significou que essa cepa foi a mais imunogênica dentre as testadas e seria a mais indicada, dentro da realidade epidemiológica da região em estudo, para que uma vacina baseada numa bacterina, fosse produzida com maior chance de sucesso. Tentativas de controle da infecção contra a $B$. pilosicoli através da vacinação foram realizadas $[7,8]$, com resultados insatisfatórios. A principal hipótese sugerida por eles para explicar essa falha vacinal foi a grande diversidade antigênica, possivelmente presente entre diferentes isolados da bactéria, o que confirmamos com o trabalho atual. Com o uso da cepa SIPV42 talvez essa dificuldade fosse atenuada, permitindo a produção de uma vacina eficiente, que seria de grande utilidade no sentido de reduzir os efeitos negativos da doença e, em especial, buscar uma redução no uso de antibióticos que são usados de forma preventiva para o controle de infecções entéricas como a colite espiroquetal.

Este trabalho descreveu várias características sorológicas dos isolados brasileiros de B. pilosicoli. Trabalhos semelhantes já haviam sido realizados com a $B$. hyodysenteriae [10], rendendo informações importantes para os veterinários que trabalham com o diagnóstico das infecções causadas pelas espiroquetas intestinais.

A realização de estudos semelhantes com as outras espécies do gênero Brachyspira, como a $B$. murdochii, B. innocens, B. intermedia, B. alvinipulli,
B. canis e, eventualmente, com a B. aalborgi, poderia fornecer uma visão mais detalhada sobre as características imunológicas desse gênero bacteriano, que apresenta grande dificuldade de controle e para os quais, talvez, as alternativas de controle via vacinação representassem a resposta mais eficiente. Em particular a $B$. aalborgi mereceria atenção especial, pois já foi isolada seres humanos e de primatas e só recentemente teve suas condições de crescimento elucidadas, abrindo um campo fértil para futuras pesquisas [17].

Pode-se inferir que o teste de microaglutinação comprovou ser uma ferramenta sensível para a avaliação das características sorológicas da B. pilosicoli, pois repetições de exames realizadas em dias diferentes apresentaram 98\% de concordância em seus resultados; existe dificuldade na leitura do teste de MAT para a B. pilosicoli em função do alto grau de autoaglutinação presente em determinados antígenos por ocasião da diluição para a realização dos testes

\section{CONCLUSÕES}

Não foi possível classificar sorologicamente as cepas brasileiras de Brachyspira pilosicoli, devido à grande quantidade de reações sorológicas cruzadas. Por reagir contra todas as cepas de B. pilosicoli contra as quais foi testado com título superiores a 1:1120, o antissoro produzido contra a amostra SIPV14 poderia ser utilizado em provas de diagnóstico, como a imuno-histoquímica e ELISA. Devido ao fato de ter reagido com todos os soros contra os quais foi testado com títulos superiores a 1:2880, a cepa SIPV42 seria a mais indicada para ser utilizada para a produção de vacina para a prevenção da infecção intestinal contra a B. pilosicoli (colite espiroquetal).

\section{REFERÊNCIAS}

1 Barcellos D.E.S.N. 2000. Infecção por Brachyspira spp. em suínos: epidemiologia e caracterização fenotípica e genotípica das espécies. 163 f. Rio de Janeiro, RJ. Tese (Doutorado em Microbiologia) - Programa de Pós-graduação em Microbiologia, Universidade Federal do Rio de Janeiro.

2 Barcellos D.E.S.N., Borowski S.M. \& Razia L.E. 2002. Avaliação do método de microaglutinação para detecção de anticorpos contra Brachyspira pilosicoli. Acta Scientiae Veterinariae. 30: 101-105.

3 Barcellos D.E.S.N., Mathiesen M., Uzeda M., Kader I.T.A. \& Duhamel G. 2000. Prevalence of Brachyspira species isolated from diarrhoeic pigs in Brazil. The Veterinary Record. 146: 398-403.

4 Baum D.H. \& Joens L.A. 1979. Serotypes of beta-hemolytic Treponema hyodysenteriae. Infection and Immunity. 25: 792-796.

5 Duhamel G.E., Elder R.O., Muniappa N., Mathiesen M.R., Wong V.J. \& Tarara R.P. 1997. Colonic spirochetal infections in nonhuman primates that were associated with Brachyspira aalborgi, Serpulina pilosicoli, and unclassified flagellated bacteria. Clinical Infectious Diseases. 25: 186-188. 
6 Hampson D.J., Mhoma J.R.L., Combs B.G. \& Lee J.I. 1990. Serological grouping of Treponema hyodysenteriae. Epidemiology and Infection. 105: 79-85.

7 Hampson D. J., Robertson I.D. \& Oxberry S.L. 2000. Influences of diet and vaccination on colonisation of pigs by the intestinal spirochaete Brachyspira (Serpulina) pilosicoli. Veterinary Microbiology. 73: 75-84.

8 Hampson D.J., Robertson I.D., Oxberry S.L. \& Pethick D.W. 1998. Evaluation of vaccination and diet for the control of Serpulina pilosicoli infection (porcine intestinal spirochetosis) [paper 56]. In: Proceedings of the 15th Congress of the International Pig Veterinary Society. v.2. ( Birmingham, U.K. ). p.56.

9 Hampson D.J. \& Trott D.J. 1995. A review - Intestinal spirochetal infections of pigs: an overview with an Australian perspective. Werribee: Australasian Pig Science Association (Manipulating Pig Production, V). 266p.

10 Joens L.A., Songer J.G., Harris D.L. \& Kinyon J.M. 1980. Comparison of selective culture and serologic agglutination of Treponema hyodysenteriae for diagnosis of swine dysentery. The Veterinary Record. 106: 245-246.

11 Kinyon J.M. \& Harris D.L. 1979. Treponema innocens, a new species of intestinal bacteria, and emended description of the type strain of Treponema hyodysenteriae. International Journal of Systematic Bacteriology. 29: 102-109.

12 Kunkle R.A., Harris D.L. \& Kinyon J.M. 1986. Autoclaved liquid medium for propagation of Treponema hyodysenteriae. Journal of Clinical Microbiology. 24: 669-671.

13 Lau T.T.A. \& Hampson D.J. 1992. The serological grouping system for Serpulina (Treponema) hyodysenteriae. Epidemiology and Infection. 109: 255-263.

14 Lee B. J. \& Hampson D. J. 1999. Lipo-oligosaccharide profiles of Serpulina pilosicoli strains and their sorological cross-reactivities. Journal of Medical Microbiology. 48: 411-415.

15 Lysons R.J. 1991. Microscopic agglutination: a rapid test for identification of Treponema hyodysenteriae. The Veterinary Record. 129: 314-315.

16 Mhoma J.R.L., Hampson D.J. \& Robertson I.D. 1992. A serological survey to determine the prevalence of infection with Treponema hyodysenteriae in Western Australia. Australian Veterinary Journal. 69: 81-84.

17 Munshi M.A. 2003. Detection by PCR and isolation assays of the anaerobic intestinal spirochaete Brachyspira aalborgi from the faeces of captive nonhuman primates. Journal of Clinical Microbiology. 41: 1187-1191.

18 Paulovich F. 2003. Avaliação da patogenicidade de amostras de Brachyspira pilosicoli através de técnicas histopatológicas convencionais e por imuno-histoquímica. 49 f. Porto Alegre, R. S. Dissertação (Mestrado em Ciências Veterinárias) - Programa de Pós-graduação em Ciências Veterinárias, Universidade Federal do Rio Grande do Sul.

19 Saunders C.N. \& Hunter D. A. 1974. Fluorescent antibody-staining technique for the diagnosis of swine dysentery. The Veterinary Record. 94: 491-492.

20 Soncini R. \& Madureira Jr. S. 1998. Monitorias sanitárias. In: Sobestiansky J., Wentz I., Silveira P.R.S. \& Sesti L.A C. (Eds). Suinocultura intensiva: produção, manejo e saúde do rebanho. Brasília: Serviço de Produção de Informação SPI, pp.91-110.

21 Sulzer C. R. \& Jones W. L. 1978. Leptospirosis: methods in laboratory diagnosis. Center for Disease Control - CDC. (HEW Publication n.79-8275). p.25.

22 Taylor D.J., Simmons J.R. \& Laird H.M. 1980. Production of diarrhoea in pigs feeding pure cultures of a spirochete differing from Treponema hyodysenteriae. The Veterinary Record. 106: 326-332.

23 Trott D. J., Alt D.P., Zuerner L.R., Wannemuehler M.J. \& Stanton T.B. 2001. The search for Brachyspira outer membrane proteins that interact with the host. Animal Health Research Reviews. 2: 19-30. 